San Jose State University

SJSU ScholarWorks

Master's Theses

Master's Theses and Graduate Research

1991

\title{
The relationship between psychological stressors, anxiety, and physical symptoms of distress in the noninstitutionalized elderly
}

Nancy M. Moran

San Jose State University

Follow this and additional works at: https://scholarworks.sjsu.edu/etd_theses

\section{Recommended Citation}

Moran, Nancy M., "The relationship between psychological stressors, anxiety, and physical symptoms of distress in the noninstitutionalized elderly" (1991). Master's Theses. 255.

DOI: https://doi.org/10.31979/etd.z6wt-b7cw

https://scholarworks.sjsu.edu/etd_theses/255

This Thesis is brought to you for free and open access by the Master's Theses and Graduate Research at SJSU ScholarWorks. It has been accepted for inclusion in Master's Theses by an authorized administrator of SJSU ScholarWorks. For more information, please contact scholarworks@sjsu.edu. 


\section{INFORMATION TO USERS}

This manuscript has been reproduced from the microfilm master. UMI films the text directly from the original or copy submitted. Thus, some thesis and dissertation copies are in typewriter face, while others may be from any type of computer printer.

The quality of this reproduction is dependent upon the quality of the copy submitted. Broken or indistinct print, colored or poor quality illustrations and photographs, print bleedthrough, substandard margins, and improper alignment can adversely affect reproduction.

In the unlikely event that the author did not send UMI a complete manuscript and there are missing pages, these will be noted. Also, if unauthorized copyright material had to be removed, a note will indicate the deletion.

Oversize materials (e.g., maps, drawings, charts) are reproduced by sectioning the original, beginning at the upper left-hand corner and continuing from left to right in equal sections with small overlaps. Each original is also photographed in one exposure and is included in reduced form at the back of the book.

Photographs included in the original manuscript have been reproduced xerographically in this copy. Higher quality $6 "$ " 9 9" black and white photographic prints are available for any photographs or illustrations appearing in this copy for an additional charge. Contact UMI directly to order.

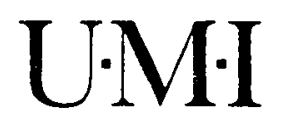

University Microfilms International

A Bell \& Howell Information Company 300 North Zeeb Road. Ann Arbor. M1 48106-1346 USA

$313 / 761-4700 \quad 800 / 521-0600$ 
Order Number 1347170

The relationship between psychological stressors, anxiety, and physical symptoms of distress in the noninstitutionalized elderly

Moran, Nancy Marie, M.S.

San Jose State University, 1991 



\title{
THE RELATIONSHIP BETWEEN PSYCHOLOGICAL STRESSORS, ANXIETY, AND PHYSICAL SYMPTOMS OF DISTRESS IN THE NONINSTITUTIONALIZED ELDERLY
}

\author{
A Thesis \\ Presented to \\ the Faculty of the Department of Nursing \\ San Jose State University \\ In Partial Fulfillment \\ of the Requirements for the Degree \\ Master of Science
}

By

Nancy M. Moran

December, 1991 
APPROVED FOR THE DEPARTMENT OF NURSING

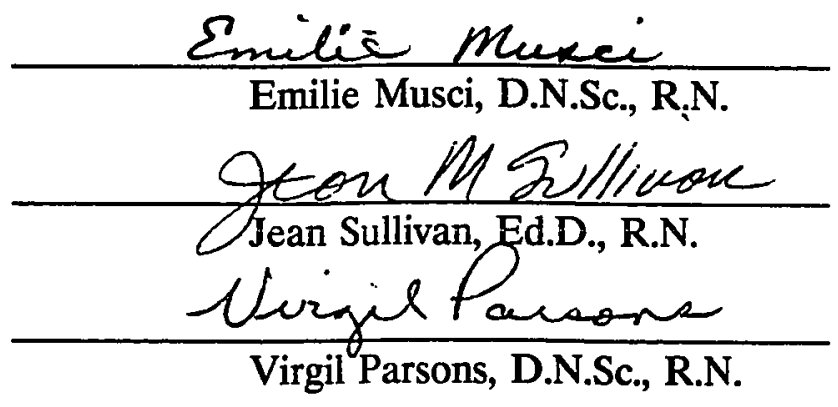

\section{APPROVED FOR THE UNIVERSITY}

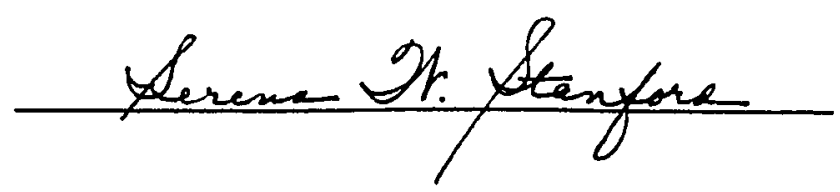




\section{ABSTRACT \\ THE RELATIONSHIP BETWEEN PSYCHOLOGICAL STRESSORS, ANXIETY, AND PHYSICAL SYMPTOMS OF DISTRESS IN THE NONINSTITUTIONALIZED ELDERLY}

by Nancy Moran

A descriptive correlational design was used to determine the relationship between psychological stressors, anxiety, and physical symptoms of distress in 41 noninstitutionalized adults. Subjects ranged in age from 65 to 88 years old. The Stokes/Gordon Stress Scale, the Spielberger State-Trait Anxiety Inventory, and the Physical Symptoms of Stress Checklist were administered to each subject. Significant positive correlations occurred between psychological stressors, anxiety, and physical symptoms of stress. Age was found to be negatively correlated with each of the variables. This finding refutes the popular belief that old age is associated with increased stress. Recommendations for further nursing research are to compare subjects with low stress scores and low physical symptoms of stress to subjects with high stress scores and high physical symptoms of stress for illness onset, and to investigate cognitive appraisal and coping styles in specific age ranges of the elderly that influence illness. 


\section{ACKNOWLEDGEMENTS}

I would like to thank Dr. Emilie Musci for her valuable guidance and support during this effort, Gary Porter for his patience and assistance in the statistical analysis section, Linda Weesner R.N. for her flexibility in scheduling, and most importantly, my husband Bob whose love, computer expertise, and willingness to manage many of the activities of daily living of our family was truly appreciated. I would also like to acknowledge the generous participants in this study whose willingness to share their experiences made this thesis possible. 
LIST OF TABLES $\ldots \ldots \ldots \ldots \ldots \ldots \ldots \ldots \ldots \ldots \ldots \ldots \ldots \ldots \ldots \ldots \ldots$

Chapter

1. INTRODUCTION $\ldots \ldots \ldots \ldots \ldots \ldots \ldots \ldots \ldots \ldots \ldots \ldots$

Problem Area $\ldots \ldots \ldots \ldots \ldots \ldots \ldots \ldots \ldots \ldots \ldots \ldots \ldots$

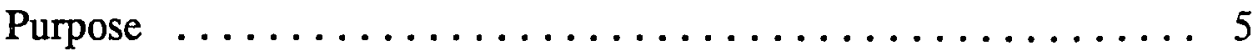

Research Questions ..................... 6

Definition of Terms $\ldots \ldots \ldots \ldots \ldots \ldots \ldots \ldots \ldots$

Summary $\ldots \ldots \ldots \ldots \ldots \ldots \ldots \ldots \ldots \ldots \ldots \ldots \ldots \ldots \ldots \ldots$

2. CONCEPTUAL FRAMEWORK AND REVIEW OF

LITERATURE $\ldots \ldots \ldots \ldots \ldots \ldots \ldots \ldots$

Conceptual Framework $\ldots \ldots \ldots \ldots \ldots \ldots \ldots \ldots \ldots$

Review of Literature $\ldots \ldots \ldots \ldots \ldots \ldots \ldots \ldots \ldots \ldots \ldots \ldots$

3. METHODOLOGY $\ldots \ldots \ldots \ldots \ldots \ldots \ldots \ldots \ldots \ldots \ldots \ldots \ldots$

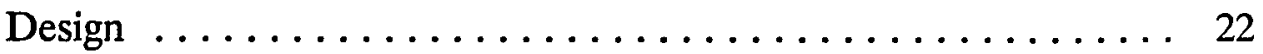

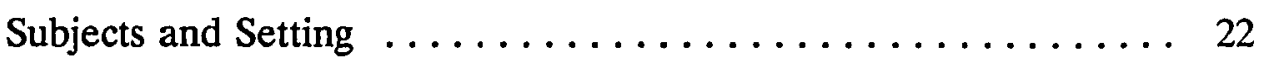

Human Subjects Approval $\ldots \ldots \ldots \ldots \ldots \ldots \ldots \ldots .24$

Data Collection ......................... 24

Instruments $\ldots \ldots \ldots \ldots \ldots \ldots \ldots \ldots \ldots \ldots \ldots \ldots \ldots \ldots \ldots \ldots \ldots$

Analysis Procedures $\ldots \ldots \ldots \ldots \ldots \ldots \ldots \ldots \ldots \ldots \ldots$ 
4. FINDINGS AND INTERPRETATION OF DATA . . . . . . . . 30

5. DISCUSSION $\ldots \ldots \ldots \ldots \ldots \ldots \ldots \ldots \ldots \ldots \ldots \ldots \ldots \ldots \ldots$

Summary of Study $\ldots \ldots \ldots \ldots \ldots \ldots \ldots \ldots \ldots \ldots \ldots \ldots, \ldots \ldots$

Conclusions . . . . . . . . . . . . . . . . . . . . . . . . 39

Scope and Limitations . . . . . . . . . . . . . . . 41

Recommendations $\ldots \ldots \ldots \ldots \ldots \ldots \ldots \ldots \ldots \ldots \ldots, 42$

REFERENCES $\ldots \ldots \ldots \ldots \ldots \ldots \ldots \ldots \ldots \ldots \ldots \ldots \ldots \ldots \ldots \ldots$

APPENDICES

A. Voluntary Informed Consent Form $\ldots \ldots \ldots \ldots \ldots$. 49

B. San Jose State Human Subjects Committee Approval ..... 52

C. Agency Consent Form $\ldots \ldots \ldots \ldots \ldots \ldots \ldots \ldots$

D. Stokes/Gordon Stress Scale .............. 57

E. Stokes/Gordon Stress Scale Permission Letter ....... 62

F. Spielberger State-Trait Anxiety Inventory . . . . . . . 64

G. Physical Symptoms of Stress Checklist $\ldots \ldots \ldots \ldots \ldots 67$ 


\section{List of Tables}

Table

Page

1. Mean, Standard Deviation and Range for Tests

in the $\underline{N}=41$ Sample $\ldots \ldots \ldots \ldots \ldots \ldots \ldots \ldots \ldots \ldots$

2. Correlation Matrix for Tests in the $\underline{N}=41$ Sample . . . . . . . . 32

3. Correlation Matrix for Tests in the $\underline{n}=20$ Sample $\ldots \ldots \ldots \ldots$

4. Correlation Matrix for Tests in the $\underline{n}=21$ Sample $\ldots \ldots \ldots \ldots$ 
Chapter 1

\section{INTRODUCTION}

Stress has been positively linked with the onset of physical illness. However, most research has been done with middle-aged populations, with little attention given to individuals 65 years of age or over (Stokes \& Gordon, 1988, p. 16). Holmes and Rahe (1967) described a stressor as an event which causes change in one's usual way of life. They postulated that such change requires adaptation and leads to an alteration in various physiologic systems, which in turn increases the risk of becoming ill (Sussman, 1987, p. 19). This concept of stress also included experiences that are generally regarded as positive or pleasant. For example, a vacation, job promotion, or marriage might require as much social readjustment as events considered to be a hardship such as the death of a spouse.

Lazarus states that psychological stress is a particular relationship between the person and the environment that is appraised by the person as manageable or as exceeding his or her resources and endangering his or her well being (Lazarus \& Folkman, 1984, p. 19). This helps to explain why one person perceives an event as stressful and another does not. The extent to which a person reacts physically to a stressor is determined by the degree of threat perceived by the individual (Stokes \& Gordon, 1988, p. 16).

While many physicians and social scientists believe stress adversely affects the health of the elderly, others argue that this relationship has not been conclusively 
established (Sussman, 1987, p. 41). There have been a number of studies that report either distress increases with age, or distress decreases with age, or that distress is unrelated to age (Feinson \& Thoits, 1986, p. 226).

\section{Problem Area}

Research on the physical and psychological effects of stress is contradictory. Furthermore, geriatric stress research is gaining more attention since the over 65 population is steadily increasing. In $1900,4 \%$ of the population (or 3.1 million) were 65 and over compared with $11.3 \%$ (25.5 million) in 1980. The projection for the year 2030 is that 1 out of 5 or $21 \%$ of the population ( 64 million) will be 65 and over (U.S. Bureau of the Census, 1983). With the over 65 population rapidly growing, more research is needed with the elderly to determine the effects of stress. Sussman (1987) identifies that the very elderly may be less, rather than more, susceptible to stress following certain life events due to the "survivorship phenomenon." Although he fails to define numerically whom he considers to be the very elderly, he states that older adults may be seen as a select group who, by virtue of reaching advanced age, have demonstrated superior adaptive abilities and have coped successfully with life stressors to reach their later years.

However, McNaughton, Smith, Patterson, and Grant (1990), in a study done with 33 middle-class elderly women, found that stress, social support, and coping are related to immune function. Highly stressed elderly women had significantly lower ratios of $\mathrm{CD}_{4}^{+}$to $\mathrm{CD}_{8}^{-}$cells $(\mathrm{t}=2.14, \mathrm{p}=.04)$ and endorsed more 
depressive items on the Brief Symptom Inventory $(\mathrm{t}=2.08, \mathrm{p}=.05)$ than did low stress women. As part of the T4 helper cells in the immune system, $\mathrm{CD}_{4}^{+}$and $\mathrm{CD}_{8}^{-}$cells help to fight off pathogens in defense of the body. It appeared that highly stressed women were at greater risk for infection in this study.

Additionally, numerous studies have shown that psychosocial factors can produce potentially damaging or lethal disturbances in cardiac function. Sudden death syndrome is frequently attributed to stress. These deaths, which occur within minutes of symptom onset, are hypothesized to be related to ventricular fibrillation and acute myocardial ischemia (Sussman, 1987, p. 41). Sussman (1987) cites Talman's (1985) work on how emotional stress can alter sympathetic activity and precipitate cardiac arrhythmias. Kennedy and Fisher (1987) studied 88 patients during acute treatment for life threatening arrhythmia. They found that follow-up mortality was significantly related to depression and cognitive impairment found at initial assessment. Although their subjects' mean age was 52 , they state that their results suggest that therapeutic advances that increase the number of arrhythmia survivors, may proportionately raise the percentage of vascular dementia cases in the elderly. Some degree of the observed morbidity and mortality may be related to depression and dementia. They recommend that psychosocial interventions to reduce sudden cardiac death focus on reduction of age related stressors, since as many as half of all sudden deaths occur in individuals aged 75 years or older (Kennedy \& Fisher, 1987, p. 56). 
Respiratory diseases have also been linked to stress. Bronchial asthma, neurogenic pulmonary edema, and hyperventilation are examples of respiratory conditions affected by stress. Crocco (1987) cites Luparello's (1968) work in which bronchial asthma patients were given inhalations of normal saline, but were told they were being given allergens or irritants. Of 40 asthma patients who were tested, 19 had a positive response with either clinical asthmatic attacks or lowered measurements of airway conductance and thoracic gas volumes. Crocco (1987) also describes hyperventilation syndromes resulting from affective response to anger, anxiety, or related emotional stress. He states that this increase in ventilation often is in preparation for escape, alleviation, or removal of stressful stimuli, or to engage in pleasurable pursuits (Crocco, 1987, p. 65).

Wolintz and Miller (1987) suggest that stress may contribute to various ophthalmologic disorders. The relationship between stress and essential blepharospasm, multiple sclerosis, thyroid ophthalmopathy, uveitis, and glaucoma is discussed with stress being presented as a precipitant (as in thyroid function), or as an exacerbator of an organic process.

Berman (1987) cites Lacey and Lacey's (1958) study which showed that individuals respond consistently and for years to different stressors with the same profile of autonomic responses. Some of these visceral responses may be learned and unlearned. They can be adaptive or maladaptive. These links between stress and psychosomatic symptoms provide support to the psychosomatic concept on the 
one hand and to the validity of therapy, which includes teaching to cope, on the other (Berman, 1987, p. 67). The association between peptic ulcer, irritable bowel syndrome, inflammatory bowel disease, and stress is based largely on correlation and inferential information (Berman, 1987, p. 73). The stress ulcer syndrome, however, can be more closely linked with stress. The pathophysiology of the events leading to stress ulcer syndrome with ulceration, gastrointestinal bleeding, and possibly death, is an important key to the understanding of how stress can lead to disease (Berman, 1987, p. 73).

In summary, many physical illnesses have been shown to be related to or caused by stress. With the over 65 population rapidly growing, more research on the effects of stress on the elderly is needed to verify if data obtained thus far in middle-age populations are consistent for older adults. Studies are needed to obtain more descriptive data regarding the relationship between psychological stressors pertinent to the older population, and anxiety and physical symptoms of distress in the noninstitutionalized elderly.

\section{Purpose}

The purpose of this study was to investigate the relationship between psychological stressors (such as life events and daily hassles), anxiety, and the incidence of physical symptoms of distress in the noninstitutionalized elderly as measured by the Stokes/Gordon Stress Scale (SGSS), the Spielberger State-Trait Anxiety Inventory, and self-reports by elderly subjects to 30 common physical and 
behavioral symptoms of distress.

\section{Research Questions}

The following research questions were asked:

1. What is the relationship between psychological stressors (such as life events and daily hassles), anxiety, and physical symptoms of distress in the noninstitutionalized elderly?

2. What is the relationship between psychological stressors and anxiety levels in the noninstitutionalized elderly?

3. What is the relationship between psychological stressors and the incidence of physical symptoms of distress in the noninstitutionalized elderly?

\section{Definition of Terms}

For the purpose of this study, the following definitions apply:

1. Psychological stressors are life events and daily hassles, such as a change in residence, retirement, or thinking about one's own death, which occur in the everyday life of people 65 years and over as measured by the Stokes/Gordon Stress Scale (Stokes \& Gordon, 1988).

2. Physical symptoms of distress are physiological responses of the body such as: (a) tachycardia, (b) hypertension, (c) perspiration, and (d) cold hands and feet. These physical responses occur through the activation or arousal of the autonomic nervous system in response to life events or daily hassles that are perceived as stressful. Physical symptoms of distress also include unpleasant 
somatic responses such as: (a) headache, (b) muscle tension, and (c) indigestion as reported by the noninstitutionalized elderly on the Physical Symptoms of Stress Checklist.

3. Noninstitutionalized elderly are men and women age 65 years and over who are living in their own home, possess the ability to care for themselves, and able to leave their home when desired (Stokes \& Gordon, 1988).

4. State anxiety is an emotional state which exists at a given moment in time and at a particular level of intensity. Anxiety states are characterized by subjective feelings of tension, apprehension, nervousness, and worry, and by activation and arousal of the autonomic nervous system as measured by the Spielberger State-Trait Anxiety Inventory (Spielberger, 1983, p. 1).

5. Trait anxiety refers to relatively stable individual differences in anxiety proneness. It is the tendency to perceive stressful situations as dangerous or threatening and to respond to such situations with elevations in the intensity of state anxiety reactions. Trait anxiety was measured using the Spielberger State-Trait Anxiety Inventory.

\section{Summary}

Research in the area of stress in the elderly has produced conflicting results. This study was designed to elicit more descriptive data regarding stressors and stress responses in the older population. By selecting a stress scale uniquely designed for life events and daily hassles most commonly experienced by the 
elderly, this study investigated the correlation between psychological stressors, anxiety, and physical symptoms of distress in the noninstitutionalized elderly. 
Chapter 2

\section{CONCEPTUAL FRAMEWORK AND REVIEW OF LITERATURE}

This chapter describes the conceptual framework upon which the study was developed. The framework explains how the elderly may perceive events or situations in their lives, and how these perceptions can then manifest themselves in emotional and physical reactions. These perceptions can lead to increased anxiety states or an increase in somatic symptomatology. This chapter also reviews previous research in the area of stress and the elderly and cites important findings and discrepancies found in the current research.

\section{Conceptual Framework}

The conceptual framework for this study is based upon the work of Richard S. Lazarus (1984). He developed the cognitive appraisal theory which states that the assessment of a situation as either stressful or benign is based on the individual's cognitive appraisal of the event and the personal and environmental resources available to cope with the situation. When people perceive the transaction as stressful and their automatic responses are ineffective, coping strategies are required. This perspective of coping includes efforts to deal with both the stressful problem (problem-focused coping) and the emotions (emotion-focused coping ) that are a consequence of the transaction (Downe-Wamboldt, 1991, p. 86). Factors that influence the pattern of coping include: (a) the ambiguity of the situation, (b) social resources, (c) individual motivation, (d) situational and 
temporal factors, and (e) the timing of stressful events in the life cycle. Cognitive appraisal and coping are viewed as mediators between the stress-personenvironment process and the long term outcomes.

Through primary appraisal, the person evaluates the transaction in one of three ways, as: (a) irrelevant, (b) benign-positive, or (c) stressful. Stress appraisals include harm/loss, threat, and challenge. In harm/loss, some damage to the person has already been sustained, such as an incapacitating injury or illness, recognition of some damage to self or social esteem, or loss of a loved or valued person. The most damaging life events are those in which central and extensive commitments are lost (Lazarus \& Folkman, 1984, p. 32).

Threat appraisals are anticipated harms or losses. When a harm/loss has occurred, threat often accompanies it due to its negative implications for the future. The adaptational function of threat is its ability to permit anticipatory coping in which the future can be anticipated, and planned for, and difficulties worked through in advance.

The third kind of stress appraisal is challenge in which the potential for gain or growth is present and is characterized by pleasurable emotions such as eagerness, excitement, and exhilaration. It is distinguished from threat in that threat centers on potential harms and is characterized by negative emotions such as fear, anxiety, and anger. Threat and challenge can occur simultaneously (Lazarus \& Folkman, 1984, p. 33). 
Secondary appraisal is the evaluation of what might and can be done to manage a stressful situation. Secondary appraisal is a crucial feature of every stressful encounter, because the outcome depends on what, if anything can be done, as well as what is at stake. It is a complex evaluative process that takes into account which coping options are available, the likelihood that a given coping option will accomplish what it is supposed to do, and the likelihood that one can apply a particular strategy or set of strategies effectively (Lazarus \& Folkman, 1984, p. 35).

Lyons and Werner (1987) reviewed 976 stress-related articles appearing in nursing journals since 1956 that used the term "stress" to look at the definitions and theoretical orientations used to conceptualize stress. They identified that stress has been defined as a stimulus, as a response, and as a transaction. They state that nursing as a discipline views human experiences as arising out of dynamic person-environment transactions and is focused on the individualized health care needs of people and that the transactional orientation to stress is consistent with nursing's view of human experiences for it permits the researcher to focus on individual differences in stress experiences (Lyons \& Werner, 1987, p. 5).

Lazarus and DeLongis (1983) state that we must abandon the simplistic notion that stress is adequately described by life events, however psychometrically sophisticated, and that it is sufficient to treat coping as a stable, overarching style 
with which people address the myriad sources of stress in their lives. They advocate an alternative approach to conceptualizing stress, one that supplements the life events strategy, and that focuses on daily hassles (the irritating, frustrating, distressing demands and troubled relationships that plague a person day in and day out). They have found this strategy of defining stress to be more useful than life events in predicting morale, psychological symptoms, and somatic illness outcomes (Lazarus \& DeLongis, 1983, p. 247).

Lazarus states that cognitive appraisal always mediates emotional reactions to a greater or lesser degree, although emotions once generated can then affect the appraisal process (Lazarus \& Folkman, 1984, p. 278). Values, commitments, and goals that are engaged in a transaction influence how a person construes a situation, and hence, the emotions he or she experiences. A person must sense threat and distinguish it from nonthreat or else be constantly in a state of psychological stress or crisis. He views emotions and cognitive processes as bidirectional. Cognitive appraisal is the mediating process that sets psychological events into motion. This includes coping activity, the emotional reaction, and the somatic changes that are part of any stress state (Lazarus \& Folkman, 1984, p. 284).

Anxiety can be expressed directly through physiological and behavioral changes. The nature of the behaviors displayed depends upon the level of anxiety. The intensity of the behaviors will increase with increasing anxiety. The 
physiological responses associated with anxiety are primarily mediated through the autonomic nervous system. Two types of autonomic responses exist, the sympathetic response activates body processes, and the parasympathetic response conserves body processes.

In a sympathetic reaction, the cortex of the brain perceives a threat and then sends a stimulus down the sympathetic branch of the autonomic nervous system to the adrenal glands. Because of a release of epinephrine, respiration deepens, the heart beats more rapidly, and arterial pressure rises. Glycogenolysis is accelerated, and the blood glucose rises. Blood is shifted away from the stomach and intestines to the heart, central nervous system, and muscles. However, for some individuals, the parasympathetic reaction may coexist or predominate and produce somewhat opposite effects. Parasympathetic responses include:

(a) "heartburn," (b) diarrhea, (c) nausea, (d) faintness, and (e) pressure to urinate.

Behavioral responses to anxiety can include: (a) restlessness, (b) physical tension, (c) tremors, (d) lack of coordination, (e) accident proneness, and (f) hyperventilation. Affective responses include: (a) tension, (b) nervousness, (c) fear, (d) fright, (e) alarm, (f) jitteriness, and (g) jumpiness. Several coping mechanisms to alleviate mild levels of anxiety include: (a) crying, (b) sleeping, (c) eating, (d) yawning, (e) laughing, (f) cursing, (g) daydreaming, as well as such oral behaviors as smoking and drinking (Stuart \& Sundeen, 1991, p. 326).

This study utilized the Stokes/Gordon Stress Scale which incorporates both 
life events and daily hassles in its content to measure psychological stressors in the noninstitutionalized elderly. The Spielberger State-Trait Anxiety Inventory is also used to measure the harm and threat components of the subjects' affective responses to their cognitive appraisal of these stressors. Lastly, subjects are asked to report the presence and frequency of 30 common physical and behavioral reactions to stress as identified in Anne Warner-Reitz's (1981) Healthy Lifestyle for Seniors to describe their physical symptoms of distress occurring in response to anxiety states and stressors.

\section{Review of Literature}

Stress in the elderly and its relation to physical illness has been studied by numerous researchers. The results have yielded conflicting evidence. Findings have generally supported a weak, but statistically significant relationship between life events and illness onset (Hyman \& Woog, 1982, p. 155). Characteristics of the environmental variables found to influence illness onset include their magnitude, for example, the extent to which they alter enduring life circumstances, their intensity, duration, and inherent ambiguity. The number of stressors present is also thought to be influential; that is, the impact of events is presumed to be additive. People's perceptions of the events rather than the events themselves seem to be the crucial factor in disease onset. Hyman and Woog (1982), citing Glass (1979) and Pearlin (1980), postulate that events promote distress only when they adversely alter the more durable conditions of life with which people must 
contend, and that illness onset is not explainable in terms of influences that currently can be measured or controlled, and also that inconsistencies of the phenomenon of stress-illness are essential and irreducible. It may be that science will never be able to predict in this area, that it is only in retrospect that the meaning of life events becomes clear, and that life events checklists are useless because they cannot possibly account for context.

Holmes and Rahe (1967) developed the Social Readjustment Rating Scale (SRRS). The implications of Holmes and Rahe's research is that persons under a great deal of perceived stress are more vulnerable to illness, and too much stress in a person's life in a relatively short time may in fact precipitate illness or even death (Thorson \& Thorson, 1986, p. 21). Thorson and Thorson (1986), citing C. Kent Smith's (1978) work, reported that the severity of illness increased in direct proportion to the individual's point count on the SRRS. It was clear that too much stress in a relatively brief part of a person's life could, and did, precipitate health changes. The greater the change, the greater the likelihood of serious illness. Thorson and Thorson (1986) also state that reactions to stress and perception of its impact change as we age. To a certain extent, the impact of life's changes is ameliorated by anticipation. Surprises are perceived as being more stressful than events that we can see coming. Sudden widowhood of a 30 year old woman might seem to be more stressful than the loss of a spouse experienced by an 80 year old whose husband has been sick for many years. The 
anticipated loss would have less impact than the sudden loss. Thorson and Thorson (1986) go on to say that assessing the combination of stress and physical frailty might lead one to the belief that the older adult would fall apart, when in fact, they are by definition the survivors. Thorson and Thorson (1986) cite McCrae's (1982) findings that older persons coped in much the same way as younger people and Bell, Kara, and Batterson's (1978) findings that older persons coped much better with a natural disaster than did younger adults.

Lazarus and DeLongis (1983) cite Golden's (1982) findings that three coping styles were evident in a sample of 100 subjects aged $45-64$ years old. They were confrontation, denial, and avoidance. It is interesting to note from Golden's findings that the evident styles involved: (a) consistent suppression of negative emotions, (b) the frequent experience of somatic symptoms such as headache and indigestion directly following the suppression of negative emotions, (c) a pervasive concern for blame, and (d) the infrequent achievement of psychological closure in stressful episodes. Lazarus, however, states that one reason cognitive appraisal of the same stimuli may change with age is that in addition to their values, beliefs, and commitments, people's expectations probably change as well (Lazarus \& DeLongis, 1983, p. 248). Costa and McCrae state that conditions like fatigue after exercise, considered medically significant by younger people, may be regarded as a normal part of aging by the elderly, who may show a realistic concern for their health without a greater number of complaints (Costa \& 
McCrae, 1980, p. 254).

Berkanovic and Hurwicz (1989), in a prospective investigation of the impact of psychological distress on the seeking of medical care among a sample of 1,009 Medicare recipients, found no relationship between psychological distress and the total number of physician visits requested by the subjects over a 1 year period. It did not appear that psychological distress had any impact on the frequency of physician visits or the medical necessity of visits made for episodes of illness. Feinson and Thoits (1986), in a study with 476 older adults aged 65 and over living in central New Jersey, found a lower prevalence of distress and depression than median rates suggested. They concluded that the prevalence of distress among older adults may be considerably lower than generally believed. A methodological difference in this study was that distress was defined as a general state of unpleasant arousal or emotion. The sample also included widows and widowers who had recently lost spouses. Depression and anxiety disorders were also included in the sample which makes it even more surprising that prevalence rates were lower.

McNaughton, Smith, Patterson, and Grant (1990), in a study done with 33 middle class elderly women, found that stress, social support, and coping are related to immune function. Highly stressed elderly women had lower immune components in immunological tests than did lesser stressed individuals. It appeared that severe threats, depressed mood, and dissatisfaction with social 
supports were related to immune suppression, whereas problem-focused coping was associated with better immune function.

Not all researchers agree that the evidence is sufficient to prove stress is an important factor in disease onset and outcome. Sussman (1987) cites Angell's (1985) remarks that the known physiologic effects of stress on the adrenal glands are often overinterpreted so that it is a short leap to a view of stress as a cause of one disease or another. ... It is not enough to point to the plausibility of a chain of events leading from emotional stress to increased adrenal activity to immune suppression to cancer.

Stokes and Gordon (1988) nonetheless found in testing the predictive validity of their geriatric stress scale, that scores on the Stokes/Gordon Stress Scale correlated significantly with the onset of illnesses for the total year $(\underline{r}=.36$, $\mathrm{p}=.014$ ) in a sample population of 46 healthy noninstitutionalized older adults. No attempt was made in this study, however, to control for chronic illnesses; thus it is impossible to distinguish which physical manifestations are secondary to stress and which to a natural progression of a disease process. Whether a person is at risk for the adverse effects of stress may be more dependent on underlying health than age.

Gottschalk (1983) also reviewed factors that increase vulnerability to disease. He identified major life change and family change events as one of a multitude of factors which increase susceptibility to cancer, infections, and other diseases. 
Cohen, Tyrrell, and Smith (1991) found that psychological stress was associated in a dose-response manner with an increased risk of acute respiratory illness, and this risk was attributable to increased rates of infection rather than to an increased frequency of symptoms after infection. In the study at the Common Cold Unit in Salisbury, England, 394 subjects, age 18 to 54, completed questionnaires assessing their degree of psychological stress. The subjects were then given nasal drops containing a respiratory virus. The subjects were quarantined and observed for evidence of infection and symptoms. Infection rates ranged from $74 \%$ to $90 \%$, according to levels of psychological stress, and the incidence of clinical colds ranged from $27 \%$ to $47 \%$. These effects were not altered when controlled for: (a) age, (b) sex, (c) education, (d) allergic status, (e) weight, (f) the season, or (g) number of subjects housed together. Several potential stress-illness mediators such as: (a) smoking, (b) alcohol, (c) exercise, (d) diet, (e) sleep, (f) white cell counts, and (g) total immunoglobulin levels did not explain the association between stress and illness (Cohen et al., 1991, p. 606).

Krause and Markides (1987), in a study with 351 older adults age 65 and over, found that illness of a spouse had an increased effect of depressive symptoms for both older men and women. For older women, the findings showed that illness of a spouse is also related to both chronic financial and marital strain, which exerted a detrimental impact on psychological well-being.

Dura, Stukenberg, and Kiecolt-Glaser (1990) compared 86 subjects (mean 
age, 68) who were caring for a spouse with progressive dementia, with 86 sociodemographically controlled subjects who were not caregivers. The strain of long term care giving was found to be linked to the onset of depressive disorders in older adults with no prior evidence of vulnerability. Dementia caregivers were significantly more dysphoric than noncaregivers.

Preston and Dellasega (1990) interviewed 900 elderly subjects age 65 to 94 years. Subjects were asked to rate their health as good or poor and were then asked a series of questions to determine low stress and high stress categories. They found that married women were in the poorest health and the most vulnerable to stress.

Most of the previous studies have used a prospective design to determine future physical illness based on current experiences of stress. This study will utilize the Stokes/Gordon Stress Scale which incorporates both life events and daily hassles in its content to look at the emotional component of anxiety which is associated with threat and physical symptoms of distress which may be occurring simultaneously with the stressor.

In summary, stress has been positively linked with the onset of physical illness; however, the majority of these studies have been done with middle aged populations, with little attention being given to individuals 65 years and over. The research which has been done with the elderly has yielded mixed results. One reason for this is the many variables which enter into the measurement of stress, 
such as life events, perception, coping, and even the definition of stress itself.

Viewing stress as a stimulus, or a response, or as a transaction between the person and the environment also influences the methodological approaches. More descriptive data is needed in the older population before definitive conclusions can be made. 
Chapter 3

\section{METHODOLOGY}

This chapter presents the methodology used in this research study. The design, setting, subjects, and data collection instruments are described as well as the analysis procedures used to interpret the data.

\section{Design}

A descriptive correlational design was used in this study to gain more information about the relationship between psychological stressors, state-anxiety, trait-anxiety, physical symptoms of stress, and age in the noninstitutionalized elderly. No attempt was made to control or manipulate these variables. This design allowed the researcher to collect data about the relationship between physical and psychological responses that occurred in subjects as a result of their transactions with their environments. It also allowed for data to be collected in a relatively short period of time consistent with the time limitations of the researcher.

\section{Subjects and Setting}

A convenience sample of 50 subjects age 65 and over were approached to participate in this study. Forty-one consented to participate; nine declined due to time constraints, unwillingness to disclose personal information, or refusal to sign written consent forms. The subjects were solicited from two senior centers that provide nutritional programs and other activities for older adults. Subjects were 
approached with these statements:

"Hello, I am a registered nurse currently working towards my master's degree in nursing at San Jose State University. I am interested in studying the relationship between stress and physical illness in the older population. I would like to invite you to participate in this study. It involves reading three forms and placing check marks next to your answers. The total time I expect this to take is 40 minutes. You do not have to participate if you do not want to do so. You can also stop participating at any time. All information will be kept confidential. If you refuse, it will not affect any service or activity you are involved with here at the Center. I will need you to sign a consent form if you do agree to participate. Thank you very much for your time. Would you like to participate?"

Thirty-two females and nine males agreed to participate. The mean age was 73 , with a range from 65 to 88 years old. Three seniors required the assistance of this researcher to read the questionnaires to them due to poor eyesight or the desire to ask questions regarding their completion. Subjects were given an envelope containing: two copies of the written consent form, the Stokes/Gordon Stress Scale, the Spielberger State-Trait Anxiety Inventory, and the Physical Symptoms of Stress Checklist. Voluntary informed consent (see Appendix A) was obtained from the participants prior to participation via written form. Subjects were asked to sign and return one copy of the consent form to the researcher and to keep one for their personal files. No attempt to control for chronic illness was 
made. No randomization of subjects was attempted.

\section{Human Subjects Approval}

Human subjects approval was obtained for this research study from the San

Jose State University Institutional Review Board in April, 1991 (See Appendix B). Written approval was also obtained from the directors of both senior centers following a written and verbal presentation of the proposed study (See Appendix C).

\section{Data Collection}

Data collection was performed between April 1991 and June 1991. A total of eight visits were made by this researcher to the two senior sites in order to procure subjects and to collect data. The Stokes/Gordon Stress Scale, the Spielberger State-Trait Anxiety Inventory, and the Physical Symptoms of Stress Checklist were administered to each participant. Completion time ranged from 15 to 40 minutes depending upon the physical and intellectual capacity of the subject. Demographic information of age, sex, and marital status was requested. Questionnaires were numerically coded to ensure confidentiality. Data were securely maintained in locked files at the researcher's home.

\section{Instruments}

The instruments for this study were: (a) the Stokes/Gordon Stress Scale to measure the amount of stressors currently being experienced by the subject, (b) the Spielberger State-Trait Anxiety Inventory to measure psychological 
appraisal of threat in the subject, and (c) the Physical Symptoms of Stress Checklist adapted from a stress management program for senior citizens to measure current symptoms of a physical stress response.

The Stokes/Gordon Stress Scale (SGSS) is a self-administered checklist of 104 items (See Appendix D). Subjects are asked to place an $\mathrm{X}$ in front of any event or situation they are currently experiencing. Items for the scale were derived from a comprehensive review of literature, interviews with individuals 65 years and over, and consultation with experts in the field of gerontology (Stokes \& Gordon, 1988). Permission to use this tool was obtained from its authors (See Appendix E).

The reliability of the SGSS was obtained by test-retest and internal consistency methods. Test-retests were conducted with three convenience samples $(\underline{\underline{n}}=11,23$, and 18). The test-retest interval was 2 weeks. The Pearson productmoment correlation for the samples were $.98(\mathrm{p}<.001), .91(\mathrm{p}<.001)$, and .90 $(\mathrm{p}<.001)$. Cronbach's alpha for internal consistency was estimated on another similar convenience sample of $\underline{\underline{n}}=63$. The alpha was .86 .

Content validity was assured by the methods used to generate the 104 items. Concurrent validity was examined by administering the SGSS, the Schedule of Recent Events (SRE) (Holmes \& Rahe, 1967) and the Geriatric Social Readjustment Scale (GSRRS) (Amster \& Kraus, 1974) to 11 additional subjects. The Pearson product-moment correlation between the SGSS and the SRE was .81 
$(\mathrm{p}<.001)$. Correlation between the SGSS and the GSRRS using the Pearson product-moment correlation was $.65(\mathrm{p}<.015)$. Predictive validity was tested through a one year correlation study with a sample of 46 subjects. The score on the SGSS at the beginning of the year correlated significantly with the onset of illnesses for the total year $(\underline{r}=.36, \underline{p}=.01)$.

The Spielberger State-Trait Anxiety Inventory (Form Y) was used to measure the anxiety levels/psychological stress of the participants (See Appendix F). Since psychological appraisal of events as stressful is necessary in Lazarus' (1984) Cognitive Appraisal Theory, a tool was needed to measure this response. The Spielberger State-Trait Anxiety Inventory comprises separate self-report scales for measuring state and trait anxiety. The S-Anxiety scale (STAI Form Y-1) consists of 20 statements that evaluate how respondents feel "right now, at this moment." The T-Anxiety Scale (STAI Form Y-2) also consists of 20 statements that assess how people generally feel. Each STAI item is given a weighted score of 1 to 4 . A rating of 4 indicates the presence of a high level of anxiety for 10 S-Anxiety items and 11 T-Anxiety items. Scores for the S-Anxiety and T-Anxiety scales can vary from a minimum of 20 to a maximum of 80 .

The Spielberger State-Trait Anxiety Inventory (STAI) has been used extensively in research and clinical practice. Normative data for Form $\mathrm{Y}$ are available for working adults, college students, high school students, and military recruits. Alpha reliabilities for working adults $(\underline{N}=1,838)$ was .93 for both males 
and females on the S-Anxiety scale and .91 for the T-Anxiety scale. The alpha coefficients for the 50-69 year old age group were .92 for males on the S-anxiety and .96 for the T-Anxiety scale. For females, the alpha coefficients on the S-Anxiety scale were .90 , and .89 for the T-Anxiety scale.

Correlations of the STAI with the Minnesota Multiphasic Personality Inventory (MMPI) were done with hospitalized male neuropsychiatric patients from two Veterans Administration (VA) Hospitals. Although the correlations between the T-Anxiety scale and individual MMPI clinical scales were roughly comparable in the two samples, the S-Anxiety-MMPI correlations were consistently higher for one group of patients than for the other group. Although the mean T-Anxiety scores for the two samples were not significantly different, the mean S-Anxiety score of $\mathbf{5 0 . 0 7}$ for the one group of patients was significantly higher than the mean S-Anxiety score of 46.20 for the other patients $(\mathrm{p}<.01)$. Correlations between the STAI scales and the Cornell Medical Index were .70 for both the S-Anxiety and T-Anxiety scales, which indicates that a large number of medical symptoms is associated with high STAI scores (Spielberger, 1983, p. 16).

The Physical Symptoms of Stress Checklist (PSS) is a 30 item list of physical symptoms adapted from a stress management program for seniors by Warner-Reitz (1981). Warner-Reitz lists a total of 50 symptoms of stress for her geriatric stress management program. The content validity of this list was based on Selye's (1975) Stress Without Distress, as well as Davis, Eshelman, and 
McKay's (1980) The Relaxation and Stress Workbook. In addition, Stuart and Sundeen (1991) validate the content of this checklist in their section on physical, cognitive, and affective responses to anxiety (Stuart \& Sundeen, 1991, p. 326). Of these 50 symptoms, this researcher chose 30 which represented a physical response to stress. Each symptom was then listed along with possible levels of frequency such as almost never, to sometimes, to often to almost always. Numerical values of 1 to 4 were given to each category in increasing level of intensity. Subjects were asked to check which symptoms they had experienced during the previous week. A minimum score of 30 and a maximum score of 120 was possible (See Appendix G). The final tool was validated by a group of nurses who have working knowledge and experience in the area of stress and physical illness in the elderly.

\section{Analysis Procedures}

Both the SGSS and the STAI were hand scored by this researcher using the score keys published by the original researchers. Likewise, the PSS was hand scored. Raw data was submitted to a statistician who utilized both descriptive and parametric correlational statistics to analyze the data. Data were analyzed using the whole sample $(\underline{N}=41)$, and also in two subgroups consisting of each individual senior site from which the subjects were obtained $(\underline{n}=20)$ and $(\underline{n}=21)$. Descriptive statistics were used to describe the mean, range and standard deviation of: (a) psychological stressors (SGSS), (b) state anxiety (SA), (c) trait 
anxiety (T'A), (d) physical symptoms of stress (PSS) and (e) age. Coefficients of determination (parametric $\underline{\mathrm{r}}$ scores) were used to determine correlations between the variables. An $\underline{F}$ test was used to determine the significance of the correlations. An independent $\underline{t}$ test was used to determine significant differences between the scores of the two subgroups $(\underline{n}=20)$ and $(\underline{n}=21)$. 


\section{Chapter 4}

\section{THE FINDINGS}

In this chapter, the results of this study are presented. Descriptive statistics are given to describe the population as well as correlations between the scores on the: (a) Stokes/Gordon Stress Scale, (b) Spielberger State-Trait Anxiety Inventory, (c) Physical Symptoms of Stress Checklist, and (d) age. The purpose of this analysis was to determine if any significant relationships occurred among the data. Additionally, the two subgroups of senior sites are independently analyzed to determine any significant findings among or between the groups.

Results

Forty-one subjects agreed to participate. Thirty-two women and nine men with a mean age of 73 and a range from 65 to 88 years old were involved in this study. Of the participants, 15 were married, 17 were widowed, five were divorced, three were single, and one was separated. STATVIEW 512+ by Abbacus Concepts, Inc. (1986) was the statistical program utilized to compute the statistics. Table 1 shows the mean, standard deviation and range for each of the five variables of: (a) psychological stressors (SGSS), (b) state-anxiety (SA), (c) trait-anxiety (TA), (d) physical symptoms of stress (PSS), and (e) age.

The mean, standard deviation, and range for psychological stressors (SGSS) may be skewed due to the fact that one respondent identified 73 out of 104 possible stressors on the stress scale. This could be related to the subject not 
Table 1

Mean, Standard Deviation, and Range for Tests in the $N=41$ Sample.

\begin{tabular}{lccc}
\hline$\underline{\text { Measurements }}$ & $\underline{\mathrm{M}}$ & $\underline{\mathrm{SD}}$ & Range \\
\hline $\begin{array}{l}\text { Psychological Stressors } \\
\text { (SGSS) }\end{array}$ & 1074.39 & 1074.38 & $0-5866$ \\
State-Anxiety (SA) & 35.02 & 10.53 & $20-59$ \\
$\begin{array}{l}\text { Trait-Anxiety (TA) } \\
\text { Physical Symptoms of }\end{array}$ & 33.51 & 10.60 & $20-54$ \\
Stress (PSS) & 44.29 & 10.82 & $31-79$ \\
Age & 72.93 & 5.66 & $65-88$
\end{tabular}

understanding the directions of the test to only identify stressors being currently experienced. Likewise, this same subject had elevated scores on the state anxiety scale (52), the trait anxiety scale (53), and the physical symptoms checklist (75), which may have also affected the mean, standard deviation, and range for these variables as well.

The raw scores on the Stokes/Gordon Stress Scale, the Spielberger State-Trait Anxiety Inventory, the Physical Symptoms of Stress Checklist, and age were then converted to standardized $\underline{\mathrm{Z}}$ scores to allow for initial comparison between the instruments. Because of the absolute scoring difference inherent in each test, comparing a score from one test with a score in another test is difficult. 
Table 2

Correlation Matrix for Tests in the $N=41$ Sample.

\begin{tabular}{|c|c|c|c|c|}
\hline & $\begin{array}{l}\text { Psycho- } \\
\text { logical } \\
\text { Stressors } \\
\text { (SGSS) }\end{array}$ & $\begin{array}{c}\text { State } \\
\text { Anxiety } \\
\text { (SA) }\end{array}$ & $\begin{array}{l}\text { Trait } \\
\text { Anxiety } \\
\text { (TA) }\end{array}$ & $\begin{array}{l}\text { Physical } \\
\text { Symptoms } \\
\text { of Stress } \\
\text { (PSS) }\end{array}$ \\
\hline $\begin{array}{l}\text { Psychological } \\
\text { Stressors (SGSS) }\end{array}$ & & & & \\
\hline State Anxiety (SA) & $.41^{*}$ & & & \\
\hline Trait Anxiety (TA) & $.55^{*}$ & $.73^{*}$ & & \\
\hline $\begin{array}{l}\text { Physical symptoms } \\
\text { of stress (PSS) }\end{array}$ & $.70^{*}$ & .29 & $.57^{*}$ & \\
\hline Age & -.22 & -.39 & -.35 & -.11 \\
\hline
\end{tabular}

Transforming raw scores into standard scores or $\underline{\mathbf{Z}}$ scores allows correlations to be computed. Next, a correlation matrix (see Table 2) was developed depicting coefficients of determination (parametric $\underline{r}$ scores) for each of the 5 variables of:

(a) psychological stressors, (b) state anxiety, (c) trait anxiety, (d) physical symptoms of stress, and (e) age for the entire population of $\underline{N}=41$. The strongest correlation in the $\underline{N}=41$ sample occurred between state anxiety (SA) and trait anxiety (TA) $(\underline{r}=.73, \underline{p} \leq .05)$, which is not surprising since this corroborates the 
already established validity of the Spielberger State-Trait Anxiety Inventory. All correlations were positive except for age. As subjects reported increasing intensities of psychological stressors, they also reported increased anxiety and physical symptoms of stress as well. However, there was a negative correlation between psychological stressors, anxiety, and physical symptoms of stress with age in this study. The lower the age of the subject, the higher the subject scored on each of the three tests. This finding lends credence to other researchers (Sussman [1987]; Thorson \& Thorson [1986]), who found that the very elderly were less susceptible to stress. It also makes sense when viewed in terms of comments made to this researcher by some of the participants who said: "I went through some of these things years ago but it doesn't bother me now"; as well as "I don't get as upset as I used to"; to "I don't have any stress." Having lived through stressful events in the past with success helped these subjects to cope with current stressors with less cognitive appraisal of threat.

In further analyzing the correlations, it is interesting to note that psychological stressors (SGSS) and trait-anxiety (TA) showed a stronger correlation $(\underline{r}=.55$, $\mathrm{p} \leq .05)$ than psychological stressors (SGSS) and state-anxiety (SA) $(\underline{r}=.41, \mathrm{p} \leq .05)$. Since state anxiety (SA) measures how the subjects are feeling "right now, at this moment" (at the time of testing), and since all of the subjects were present at a senior site where socialization and activity were occurring, it may be that the effect of social support had an impact on the subjects' state level of anxiety. 
Additionally, the effect of the researcher establishing a trusting rapport with the subjects may have influenced their state level of anxiety at the time of testing. It seems that the overall tendency of a subject to perceive events or hassles as threatening is more closely related to psychological stressors than transient anxiety states.

Psychological stressors (SGSS) were also significantly correlated $(\underline{r}=.70$, $\mathrm{p} \leq .05)$ with physical symptoms of stress (PSS). The higher the subjects scored on the stress scale, the more physical symptoms of stress they reported. Physical symptoms of stress (PSS) and trait-anxiety (TA) were significantly correlated $(\underline{r}=.57, \underline{p} \leq .05)$. The autonomic response occurred with more frequency in subjects who had a propensity to perceive stressors as threatening. However, physical symptoms of stress (PSS) and state-anxiety (SA) were only weakly correlated $(\underline{r}=.29)$ and not significant at the .05 level. Again, this may be due to environmental influences on the subjects' state anxiety at the time of testing. The data were then analyzed by looking at each individual subgroup. The first group $(\underline{n}=20)$ was solicited from a senior site located in an affluent area in Central California. Table 3 presents correlation scores for the $\underline{n}=20$ subgroup. Correlation scores were significant for state (SA) and trait anxiety (TA) $(\underline{r}=.63$, $\mathrm{p} \leq .05$ ), and for psychological stressors (SGSS) and physical symptoms of stress (PSS) ( $\mathrm{r}=.52, \underline{\mathrm{p}} \leq .05)$. Positive correlations occurred between all of the tests but were not all significant at the .05 level. 
Table 3

Correlation Matrix for Tests in the $n=20$ Sample.

\begin{tabular}{lcccc}
\hline & $\begin{array}{c}\text { Psycho- } \\
\text { logical } \\
\text { Stressors } \\
\text { (SGSS) }\end{array}$ & $\begin{array}{c}\text { State } \\
\text { Anxiety } \\
\text { (SA) }\end{array}$ & $\begin{array}{c}\text { Trait } \\
\text { Anxiety } \\
\text { (TA) }\end{array}$ & $\begin{array}{c}\text { Physical } \\
\text { Symptoms } \\
\text { of Stress } \\
\text { (PSS) }\end{array}$ \\
$\begin{array}{l}\text { Psychological } \\
\text { Stressors (SGSS) }\end{array}$ & & & & \\
State Anxiety (SA) & .43 & & & \\
Trait Anxiety (TA) & .43 & $.63^{*}$ & & \\
$\begin{array}{l}\text { Physical symptoms } \\
\text { of stress (PSS) }\end{array}$ & $.53^{*}$ & .65 & .16 & \\
Age & & & & \\
\hline
\end{tabular}

Note. ${ }^{*}$ scores are significant at the $\mathrm{p} \leq .05$ level

Table 4 presents data from the second group $(\underline{n}=21)$. When these data were analyzed, a higher correlation between trait anxiety (TA) and physical symptoms of distress (PSS) occurred $(\underline{r}=.72, \underline{p} \leq .05)$ than for the $\underline{n}=20$ sample $(\underline{r}=.16, \underline{p} \leq .05)$. The $(\underline{n}=21)$ group was solicited from a senior site located in a much less affluent area of Central California in which crime and drug use are 
Table 4

Correlation Matrix for Test in the $n=21$ Sample.

\begin{tabular}{lcccc}
\hline & $\begin{array}{c}\text { Psycho- } \\
\text { logical } \\
\text { Stressors } \\
\text { (SGSS) }\end{array}$ & $\begin{array}{c}\text { State } \\
\text { Anxiety } \\
\text { (SA) }\end{array}$ & $\begin{array}{c}\text { Trait } \\
\text { Anxiety } \\
\text { (TA) }\end{array}$ & $\begin{array}{c}\text { Physical } \\
\text { Symptoms } \\
\text { of Stress } \\
\text { (PSS) }\end{array}$ \\
$\begin{array}{l}\text { Psychological } \\
\text { Stressors (SGSS) }\end{array}$ & .37 & & & \\
State Anxiety (SA) & $.60^{*}$ & $.78^{*}$ & & \\
$\begin{array}{l}\text { Trait Anxiety (TA) } \\
\text { Physical symptoms }\end{array}$ & $.71^{*}$ & .34 & $.72^{*}$ & \\
of stress (PSS) & & & & \\
Age & -.18 & -.41 & -.36 & -.12 \\
\hline
\end{tabular}

Note. ${ }^{*}$ scores are significant at the $\mathrm{p} \leq .05$ level

more prevalent in the surrounding community. To determine if the difference between trait-anxiety and physical symptoms of stress in the two groups was significant, an $\underline{F}$ test was performed. The difference of -.56 was found to be significant $(\underline{F}(1,18)=8.18, \underline{p} \leq .05)$. This suggests that the $\underline{n}=21$ group had a significantly higher correlation between trait anxiety states and physical 
manifestations of stress. Since trait anxiety reflects the tendency to perceive stressful situations as dangerous or threatening, it may be that the subjects who live in a lower socioeconomic community with more inherent danger present on a daily basis, cognitively appraise stressors as harmful and respond with increased somatic symptomatology. Psychological stressors (SGSS) were significantly related to physical symptoms of stress (PSS) $(\mathrm{r}=.71, \underline{\mathrm{p}} \leq .05)$ and to trait anxiety (TA) $(\underline{r}=.60, p \leq .05)$ in this group as well. Again, state-anxiety $(\mathrm{SA})$ and trait-anxiety (TA) were highly correlated $(\underline{r}=.78, \underline{p} \leq .05)$.

To determine if the differences between the two groups were statistically significant or chance occurrences, an unpaired $\underline{t}$ test was performed on each of the means of the variables. The only significant finding was that the mean scores on the Stokes/Gordon Stress Scale were significantly different $(\underline{t}(39)=-2.07, \underline{p} \leq .05)$. The mean for the $\underline{n}=20$ group was 681 and 1349 for the $\underline{n}=21$ group. The less affluent group had more psychological stressors than did the wealthier group. The two groups did not show significant differences on the anxiety or physical symptoms of stress tests.

In summary, the results show that psychological stressors, anxiety, and physical symptoms of stress are positively correlated in the noninstitutionalized elderly. However, age was found to be negatively correlated with these variables disputing earlier studies that the very elderly are more susceptible to stress. 


\section{Chapter 5}

\section{DISCUSSION}

In this chapter, a summary of the study is presented. Conclusions are discussed, and the scope and limitations of this study are given. In addition, recommendations for future nursing research in the area of stress and the elderly are presented in light of the present findings.

\section{Summary}

A convenience sample of 41 elderly men and women aged 65 and over selected from two senior sites voluntarily agreed to participate in this study. A descriptive correlational design was used to assess the relationship between psychological stressors, anxiety, and physical symptoms of distress in the noninstitutionalized elderly. The Stokes/Gordon Stress Scale, the Spielbeger State-Trait Anxiety Scale, and the Physical Symptoms of Stress Checklist were administered to each subject. Coefficients of determination (parametric $\underline{\mathbf{r}}$ scores) were used to determine a positive correlation between the variables of psychological stressors, anxiety, and physical symptoms of distress. Significant correlations occurred between state-anxiety (SA) and trait-anxiety (TA), and between psychological stressors (SGSS) and physical symptoms of stress (PSS). Psychological stressors (SGSS) and trait-anxiety (TA) states were also highly correlated, as were trait-anxiety (TA) and physical symptoms of stress (PSS). Psychological stressors (SGSS) and state-anxiety (SA) also showed a significant 
correlation.

A negative correlation occurred between age and each of the three tests administered. As the subject's age increased, the scores on each of the three tests decreased, although this was not shown to be significant at the .05 level of confidence.

The two subgroups $(\underline{n}=21)$ and $(\underline{n}=20)$, representing each of the two senior sites, were compared for significant differences. An independent $\underline{t}$ test was performed on each of the variables of psychological stressors, state-anxiety, traitanxiety, and physical symptoms of stress between the two subgroups. The $(\underline{n}=21)$ subgroup had significantly higher psychological stressors than did the $(\underline{n}=20)$ group. There was no significant difference between anxiety and physical symptoms of stress scores.

The only significant difference between the correlations of the variables in the two subgroups occurred in the correlation between trait-anxiety (TA) and physical symptoms of stress (PSS). The less affluent group had a significantly higher correlation between their proneness to anxiety and presence of physical symptoms of stress.

\section{Conclusions}

Based on the results of this study, some tentative conclusions can be reached:

1. There is a positive correlation between psychological stressors, anxiety, and physical symptoms of distress in the noninstitutionalized elderly in this sample. 
2. As age increased, the amount of stressors, anxiety, and physical symptoms of distress decreased. The elderly in this study were not more vulnerable to stress as they aged.

3. Psychological stressors are strongly correlated with physical symptoms of distress in this sample.

4. Physical symptoms of stress were significantly correlated with trait-anxiety and not with state-anxiety in this sample.

In explaining the conclusions in terms of Lazarus' Cognitive Appraisal Theory, the results show that although state-anxiety was weakly, but not significantly, correlated with physical symptoms of distress, trait-anxiety (the propensity to react to stressors with increased anxiety states) was highly correlated with physical symptoms of distress. The tendency to view stressors as threatening during the primary appraisal process may have influenced the somatic reaction to the stressor. One reason that state-anxiety scores may not have been elevated was that subjects were solicited from senior centers where socialization and activities were occurring. The effects of social support or other buffering mechanisms were not measured or controlled in this study. The results concur with the findings of Sussman (1987), that stress does not necessarily increase with age, and Costa and McCrae's (1980) findings, that the elderly may cope with stress better as they age. The correlation between psychological stressors and physical symptoms of distress is also consistent with recent findings (Cohen, Tyrell, \& Smith, 1991), that 
psychological stress is correlated with physical symptomatology.

Scope and Limitations

The scope of this study was to investigate the relationship between psychological stressors as measured by the Stokes/Gordon Stress Scale (SGSS), anxiety as measured by the Spielberger State-Trait Anxiety Scale (STAI), and physical symptoms of distress as measured by the Physical Symptoms of Stress Checklist (PSS) in 50 noninstitutionalized elderly subjects age 65 and over, at two senior sites during the months of April - June 1990. At home interviews or longitudinal data collection in a prospective method were not included.

Limitations to this study include the small sample size, the lack of randomization, and the influence of confounding variables which were not controlled in the design. Since chronic illnesses are common in the elderly, some of the physical symptoms of stress (such as high blood pressure) could be related to a coexisting hypertensive condition and not necessarily related to psychological stressors. Since stress is such a multivariate phenomenon, it is extremely difficult to measure responses in a controlled manner.

Other limitations included the fact that some elderly people refused to participate in the study which leads one to question if certain characteristics were present in the subjects who did agree to participate; that is, did they appraise participation as benign-positive or irrelevant and nonstressful instead of stressful which may have biased the study from the onset. The effect of the researcher 
assisting three participants to complete the questionnaires by reading the questions to them may also have influenced the results. The Hawthorne effect of being studied may also apply since many of the subjects approached the researcher and stated, "I don't have any stress," in a rather worried way which may have influenced their state-anxiety scores.

Another limitation was the setting from which the sample was obtained. Senior sites allow for easy access to the elderly; however, the buffering effects of social support, activity, and involvement could not be controlled. Data results depended on the truthfulness of the respondents as well. Finally, the small sample size does not allow these results to be generalized to all sociodemographic populations.

\section{Recommendations}

As a result from this study, the following recommendations are given for future nursing research in this area:

1. A replication of this study using a larger sample size and randomization in the selection process should be done.

2. A prospective study should be developed to compare subjects with high psychological stressors and physical symptoms of stress scores to subjects with low stressor and physical symptoms of stress scores for illness onset to see what coping behaviors influence physical symptoms of distress and illness onset.

3. Reliability and validation of the Physical Symptoms of Stress Checklist as 
an accurate tool of measurement should be further investigated.

4. Additional studies breaking down the age ranges of the elderly in 10 year intervals, for instance, $60-70,71-80,81-90$, to test for differences in stress related coping styles and illness onset in individuals developmentally need to be undertaken.

5. Further development of the Stokes/Gordon Stress Scale is needed so that specific scores can have predictive validity in illness onset.

6. Additional descriptive studies to look at stress in the homebound elderly which were not included in this study should be performed. 
References

Amster, L. E., \& Kraus, H. H. (1974). The relationship between life crises and mental deterioration in old age. International Journal of Aging and Human Development, 5, 51-55.

Angell, M. A. (1985). Disease as a reflection of the psyche. New England Journal of Medicine, 312(24), 1570-1572.

Bell, B. D., Kara, G., \& Batterson, C. (1978). Service utilization and adjustment patterns of elderly tornado victims in an American disaster. Mass Emergencies, $3,71-81$.

Berkanovic, E., \& Hurwicz, M. L. (1989). Psychological distress and the decision to seek medical care among a medicare population. Medical Care, 27(11), 1058-1075.

Berman, A. J. (1987). Stress and the gastrointestinal tract. Mount Sinai Journal of Medicine, $\underline{54}(1), 66-77$.

Cohen, S., Tyrrell, D., \& Smith, A. (1991). Psychological stress and susceptibility to the common cold. New England Journal of Medicine, $\underline{325}(9), 606-611$.

Costa, P.T., \& McCrae, R. R. (1980). Somatic complaints in males as a function of age and neuroticism: A longitudinal analysis. Journal of Behavior Medicine, 3 , 245-258. 
Crocco, J. A. (1987). Stress and the lung: Hypersensitivity of airways, neurogenic pulmonary edema, and hyperventilation syndrome. Mount Sinai Journal of Medicine, 54(1), 63-65.

Davis, M., Eshelman, E. R., \& McKay, M. (1980). The relaxation and stress workbook. Richmond, CA: New Harbinger Publications.

Downe-Wamboldt, B. (1991). Stress, emotions, and coping: A study of elderly women with osteoarthritis. Health Care for Women International, 12(1), 85-98.

Dura, J., Stukenberg, K., \& Kiecolt-Glaser, J. (1990). Chronic stress and depression in older adults. Journal of Abnormal Psychology, 99(3), 284-289.

Feinson, M. C., \& Thoits, P. A. (1986). The distribution of distress among elders. Journal of Gerontology, 41(2), 225-233.

Glass, G. V. (1979). Policy for the unpredictable. Educational Researcher, $\underline{8}(9)$, $12-14$.

Golden, G. (1982). Coping with aging: Denial and avoidance in middle aged caregivers. Unpublished doctoral dissertation, University of California, Berkley.

Gottschalk, L. A. (1983). Vulnerability to stress. American Journal of Psychotherapy, 37(1), 5-23. 
Holmes, T., \& Rahe, H. (1967). The social readjustment scale. Journal of Psychosomatic Research, 11(1), 213-215.

Hyman, R., \& Woog, P. (1982). Stressful life events and illness onset: A review of crucial variables. Research in Nursing and Health, $\underline{5}, 155-163$.

Kennedy, G. J., \& Fisher, J. D. (1987). Aging, stress, and sudden cardiac death. Mount Sinai Journal of Medicine, 51(1), 56-62.

Krause, N., \& Markides, K. (1987). Illness of spouse and psychological well-being in older adults. Comprehensive Gerontology, 1(3), 105-108.

Lacey, J. I., \& Lacey, B. C. (1958). Verification and extension of the principle of autonomic response stereotyping. American Journal of Psychology, 11 , (5073).

Lazarus, R. S., \& DeLongis, A. (1983). Psychological stress and coping in aging.

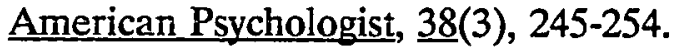

Lazarus, R. S., \& Folkman, S. (1984). Stress, appraisal, and coping. New York: Springer.

Luparello, T., Lyons, H. A., \& McFadden, E. R. (1968). Influences of airway reactivity in asthmatic subjects. Psychosomatic Medicine, $\underline{30}, 819-825$.

Lyon, B. L., \& Werner, J. S. (1987). Stress. Annual Review of Nursing Research, $\underline{5}, 3-22$.

McCrae, R. R. (1982). Age differences in the use of coping mechanisms. Journal of Gerontology, 71, 802-809. 
McNaughton, M. E., Smith, L. W., Patterson, T. L., \& Grant, I. (1990). Stress, social support, coping resources, and immune status in elderly women. $\underline{\text { Journal of Nervous and Mental Disorders, }} \underline{178},(7), 460-461$.

Pearlin, L. I. (1980). Life strains and psychological distress among adults. In N. H. Smelser \& E. Erikson (Eds.), Themes of work and love in adulthood (pp. 174-192). Cambridge, Mass.: Harvard University Press.

Preston, D., \& Dellasega, C. (1990). Elderly women and stress: Does marriage make a difference? Journal of Gerontological Nursing, 16(4), 26-32.

Seldman, D., \& Gagnon, J. (1986). Statview 512+ [Computer program]. Berkley, CA: Abbacus Concepts, Inc.

Selye, H. (1975). Stress without distress. New York: The New American Library.

Smith, C. K., Cullison, S. W., \& Polis, E. (1978). Life change and illness onset. Journal of Family Practice, 7, 975-981.

Spielberger, C. D. (1983). Manual for the state trait anxiety inventory. Palo Alto: Consulting Psychologists Press, Inc.

Stokes, S. A., \& Gordon, S. E. (1988). Development of an instrument to measure stress in the older adult. Nursing Research, 37(1), 16-19.

Stuart, G. W., \& Sundeen, S. (1991). Principles and practice of psychiatric nursing (4th ed.). St. Louis: Mosby. 
Sussman, N. (1987). Stress and medical illness in the elderly. Mount Sinai Journal of Medicine, $\underline{54}(1), 41-46$.

Talman, W. T. (1985). Cardiovascular regulation and lesions of the central nervous system. Annals of Neurology, 18(1), 1-12.

Thorson, J. A., \& Thorson, J. R. (1986). How accurate are stress scales? Journal of Gerontological Nursing, 12(1), 21-24.

U. S. Bureau of the Census. (1983). America in transition: An aging society (Series P-73 No. 128). Washington, DC: U. S. Government Printing Office.

Warner-Reitz, A. (1981). Healthy lifestyle for seniors. New York: Meals for Millions/Freedom from Hunger Foundation.

Wolintz, A. H., \& Miller, C. F. (1987). Stress and visual function. Mount Sinai Journal of Medicine, $\underline{54}(1), 78-85$. 


\section{APPENDIX A}

\section{Voluntary Informed Consent Form}


Responsible Investigator: Nancy Moran R.N.

Title of Protocol: The Relationship Between Psychological Stressors, Anxiety, and Physical Symptoms of Distress in the Non-Institutionalized Elderly

I have been asked to participate in a research study that is investigating the relationship between psychological stressors, anxiety, and physical symptoms of distress in the non-institutionalized elderly. The results of this study should further an understanding of how stress relates to physical illness in the elderly.

I understand that:

1.) I will be asked to complete both the Stokes Gordon Stress Scale questionnaire and the State-Trait Anxiety Inventory which will take between 15 and 30 minutes to complete. I will then be asked to list any physical symptoms of distress I am currently experiencing.

2.) No anticipated risks are expected from my participation in this study.

3.) The possible benefits of this study to me are that I may be able to identify stressful situations in my life for which I could then seek help.

4.) The results of this study may be published, but any information from this study that can be identified with me will remain confidential and will be disclosed only with my permission.

5.) Any questions about my participation in this study will be answered by Nancy Moran R.N. at 649-6072. Complaints about the procedures may be presented to Bobye Gorenberg DNSc. at 924-2000. For questions or complaints about research subject's rights, or in the event of researchrelated injury, contact Serena Stanford Ph.D. (Associated Academic Vice President for Graduate Studies and Research) at 924-2480.

6.) My consent is given voluntarily without being coerced; I may refuse to participate in this study or in any part of this study and I may withdraw at any time, without prejudice to my relations with SJSU or the Oldemeyer or Carmel Foundation Senior Centers. 
School of the Applied Arts and Sciencas - Departmeni of Nursing

One Washington Square - San José. Calitornia 95192-0057 • 408/924-3130

7.) My refusal to participate in this study will not affect my right to receive services at either the Oldemeyer or Carmel Foundation Senior Centers that I might normally receive.

8.) I have received a copy of this consent form for my file.

I HAVE MADE A DECISION WHETHER OR NOT TO PARTICIPATE. MY SIGNATURE INDICATES THAT I HAVE READ THE INFORMATION PROVIDED ABOVE AND THAT I HAVE DECIDED TO PARTICIPATE. 
APPENDIX B

San Jose State Human Subjects Committee Approval 
Oillce of the Academlc Vice President - Assoclate Academlc VIce President - Graduato Studies and Fesearch

One Washington Square • San Jose, Calilornia 95192-0025 • 408/924-2480

To: Nancy Moran, Nursing

579-H Wilkes Lane

Monterey, CA 93940

From: Charles R. Bolz

Office of Graduate studies and Research

Date: Apri1 23, 1991

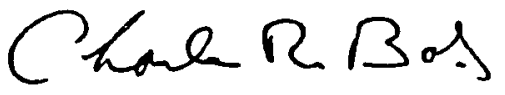

The Human Subjects Institutional Review Board has approved your request to use human subjects in the study entitled:

\section{"The Relationship Between Psychological}

stressors, Anxiety, and Physical symptoms of

Distress in the Non-Institutionalized Elderly"

This approval is contingent upon the subjects participating in your research project being appropriately protected from risk. This includes the protection of the anonymity of the subjects' identity when they participate in your research project, and with regard to any and all data that may be collected from the subjects. The Board's approval includes continued monitoring of your research by the Board to assure that the subjects are being adequately and properly protected from such risks. If at any time a subject becomes injured or complains of injury, you must notify Dr. Serena stanford immediately. Injury includes but is not limited to bodily harm, psychological trauma and release of potentially damaging personal information.

Please also be advised that each subject needs to be fully informed and aware that their participation in your research project is voluntary, and that he or she may withdraw from the project at any time. Further, a subject's participation, refusal to participate or withdrawal will not affect any services the subject is receiving or will receive at the institution in which the research is being conducted.

If you have any questions, please contact Dr. stanford or me at (408) 924-2480.

cc: Dr. Emilie C. Musci 


\section{APPENDIX C}

\section{Agency Consent Form}




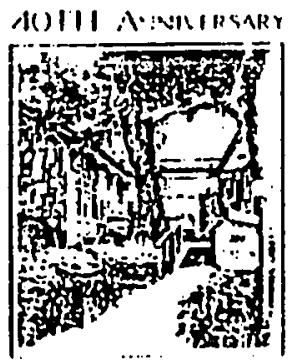

April 1, 1991

C. A R AI I: 1 .

IOINNATION

Iluman Subject Review Board

San Jose State University

One Washington Square

San Jose, CA

Dear Sirs:

I have been fully informed of the intent by Nancy Moran R.N. to conduct her nursing research study entitled, "The Relationshj.p Between Psychological Stressors, Anxiety, and Physical Synptoms of Di.stress in the Non-1nstitutiomalizerl Feluerly here at the Carmel Foumbation. I hereby give ponnission for her to collect her data at the Camel Foundation after. volumtary consent is obtained fran participants.

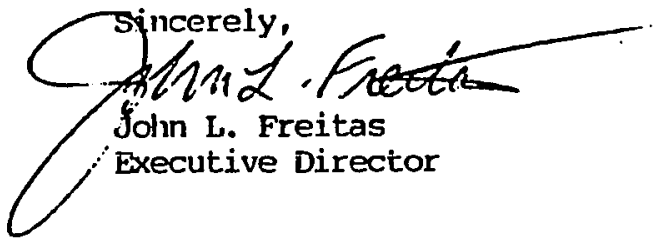




\section{CITY OF DEPSDE}

440 HARCOURT AVE

P.O. Box 810

SEASIDE. CALIFORNIA 93955.0810

TELEPHONE $(408) 809.62$

AN EOUAL ORPOHUNITY EMTLOTE.H M/F/V/M

March 26, 1991

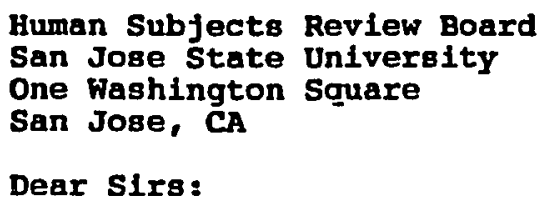

I have been fully Informed of the intent by Nancy Moran R.N. to conduct her nursing research study entitled, "The Relationship Between Paychological Stressors, Anxlety and Physical Symptoms of Distress in the Non-Institutionalized Elderly" here at the oldemeyer Center. I hereby give permission for her to collect her data at the oldemeyer Center after voluntary consent 18 obtained from participants.

sincerely,

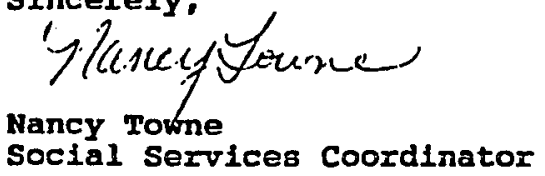

/n1t

G A TEWAYTO THE MONTEREY PENINSULA 
APPENDIX D

Stokes/Gordon Stress Scale 
PLEASE NOTE

\begin{abstract}
Copyrighted materials in this document have not been filmed at the request of the author. They are available for consultation, however, in the author's university 1 ibrary.
\end{abstract}

$58-61,65-66$

University Microfiims Internationai 
APPENDIX E

Stokes/Gordon Stress Scale Permission Letter 
PERMISSION PURM

Tille of Resentcli:

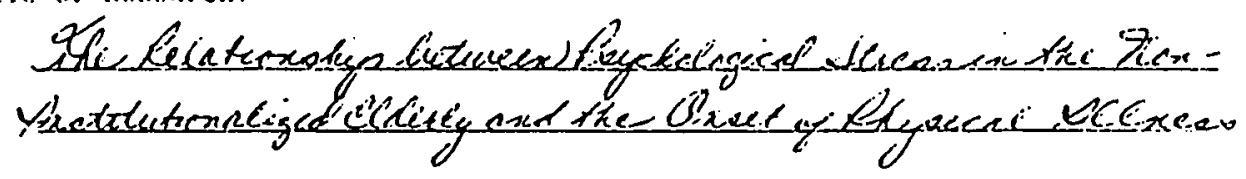

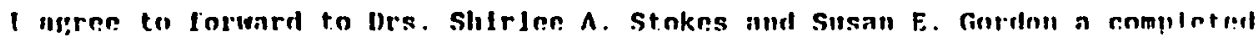

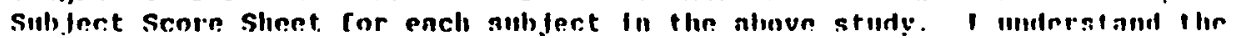

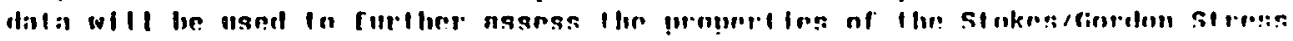
Si:nle. I understand brs. Stokes nut boldon wlll not use the dala lur suly

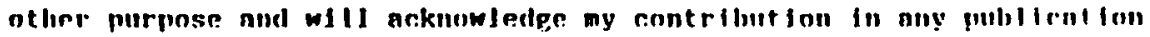
regarding the properties of the scole resulting from the datn submitted.

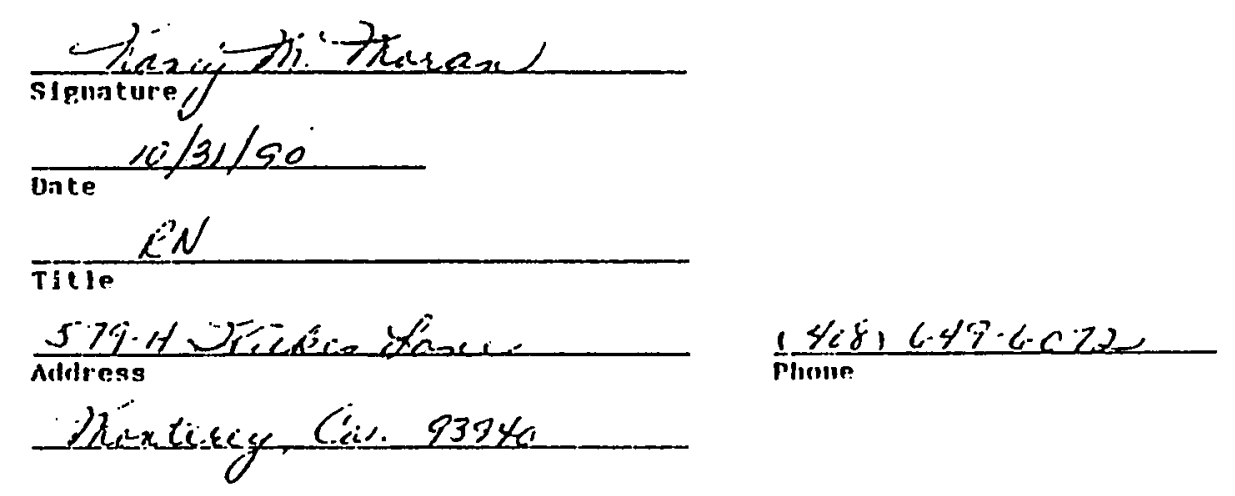

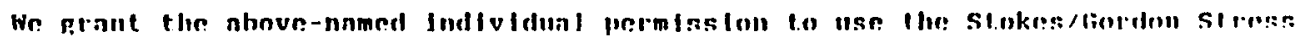
Senle In the resenteli stutly deserfbed nluve.

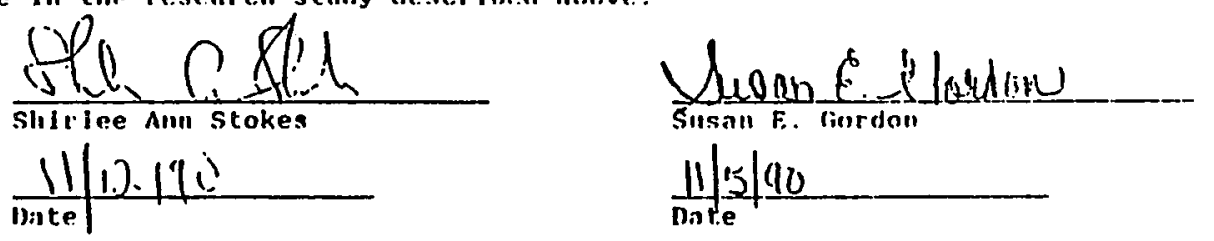

RETURN TO:

Stokes/Gordon Stress study

Llenhard School of Nursing

Pace Untueralty

Bedford Rond

Pleasantullie. NY 10570 
APPENDIX F

Spielberger State-Trait Anxiety Inventory 
APPENDIX G

Physical Symptoms of Stress Checklist 
Participation Number

Age

Sex

SGSS Score

Marital Status

STA1 Score

DIRECTIONS: Read each symptom below. Place an $\mathrm{X}$ in the appropriate space to the right of the symptom to indicate how often you have experienced this during the past week.

1. Eat too much of what you shouldn't

2. Restless

3. Cold, Flu

4. Teary

6. Insomnia

6. Headaches

7. Loss of Balance

8. Constipation

9. Diarrhea

10. Coughing

11. Accident Prone

12. Irritable

13. Tension in Neck/Other Muscle Tension

14. Severe Illness

15. Heart Palpitation

16. Rise in Blood Pressure

17. Tired

18. Perspiration

19. Hyperactive

20. Rise in Pulse Rate

21. Less Energy

22. Can't Relax or Rest

23. Loss of Appetite

24. Asthma Attack

25. Butterflies in Your Stomach

26. Indigestion

27. Tired Eyes

28. Cold Hands and Feet

29. Drinking Too Much Alcohol

30. Smokes more
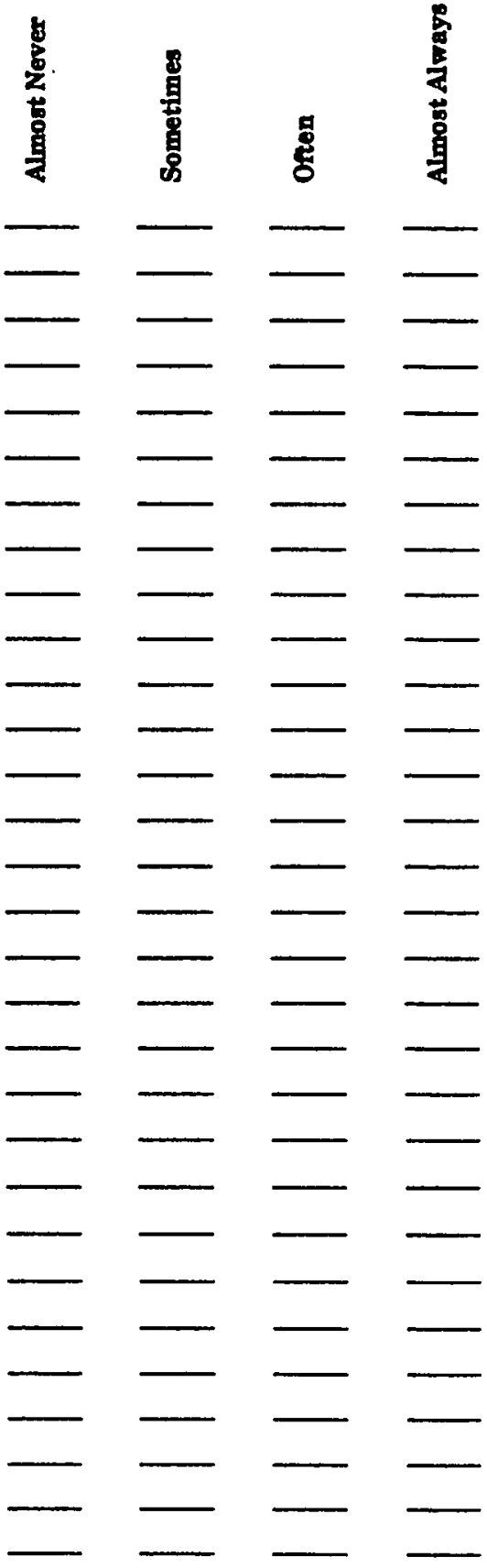